\title{
2-(2-(Tert-Butoxycarbonyl) Propanamido) Acetic Acid 'NCA- AG' Synthesis, Characterization and Reaction Optimization for the Preparation
}

\author{
Estella Judith Salamula ${ }^{1,2}$, Martin Bredenkamp ${ }^{3}$, Deon Bezuidenhout ${ }^{4}$, \\ Misael Silas Nadiye-Tabbiruka ${ }^{5, *}$ \\ ${ }^{1}$ Department of Chemistry, Institute of Polymer Science Stellenbosch University, Stellenbosch, South Africa \\ ${ }^{2}$ Department of Chemistry, College of Maths and Science, Makerere University, Kampala, Uganda \\ ${ }^{3}$ Department of Chemistry, Asia International Pacific University, Muak Lek Subdistrict, Saraburi Province, Bangkok, Thailand \\ ${ }^{4}$ University of Cape Town, Western Cape, Biomaterial Sciences Laboratories at the Cardiovascular Research Unit (CRU), Cape Town, South \\ Africa \\ ${ }^{5}$ Department of Chemistry, University of Botswana, Gabarone, Botswana
}

\section{Email address:}

matsciejs@gmail.com (E. J. Salamula),artinb@apiu.edu (M. Bredenkamp), deon.bezuidenhout@uct.ac.za (D. Bezuidenhout), nadiyem@mopopi.ub.bw (M. S. Nadiye-Tabbiruka)

\section{To cite this article:}

Estella Judith Salamula, Martin Bredenkamp, Deon Bezuidenhout, Misael Silas Nadiye-Tabbiruka. 2-(2-(Tert-Butoxycarbonyl) Propanamido) Acetic Acid 'NCA-AG' Synthesis, Characterization and Reaction Optimization for the Preparation. Advances in Biochemistry. Vol. 3, No. 6, 2015, pp. 72-76. doi: 10.11648/j.ab.20150306.12

\begin{abstract}
NCA-AG) was for the first time prepared using a variation of the Leuchs method. All compounds were characterized using melting point, nuclear magnetic resonance (NMR), ultra violet spectroscopy (UV), Fourier transform infrared spectroscopy (FTIR) and electron spray mass spectroscopy (ESMS). The reaction was optimised to obtain the highest yield by varying the reaction conditions namely; solvent, lewis acid and temperature.
\end{abstract}

Keywords: 2-(2-(Tert-Butoxycarbonyl) Propanamido) Acetic Acid (NCA-AG), Stereospecific Peptides,

Synthetic Silk Substrates, N-Tert-Butoxy Carbonanhydride (NCA)

\section{Introduction}

NCAs were initially made in the $1920 \mathrm{~s},[1,2]$ using a single amino acids and more recently, by Deming et al. [3] Interest in this area has increased thereafter where polymers such as poly-glycolides and their co-polypeptides are now used as substitutes for proteins. Some applications include preparation of tissue scaffolding and drug delivery $[4,5,6]$ as well as synthetic wool and silk substitutes. [7] Three methods have been utilized to synthesize "NCA" monomers; those are the Leuch's, Fuchs Farthing and Silyazide method. The most frequently used methods are the Leuch's and Fuchs Farthing due to the ease of the removal of bi-products.

The 'Fuch Farthing' method arises from the use of triethyl phosphate, phosgene or its derivatives (triphosgene), at low temperatures, in inert solvents such as dioxin. Trisphogene $\left(\mathrm{CO}\left(\mathrm{O}_{2} \mathrm{CCl}_{3}\right)\right)_{2}$ undergoes a nucleophilic attack at the carbonyl carbon. Trichloromethoxy $\left(\mathrm{Cl}_{3} \mathrm{CO}^{-}\right)$, [8] the leaving group dissociates to a chloride anion and a molecule of phosgene, which reacts immediately. Triphosgene is typically used as an alternative to phosgene, due to it being much safer, easier handling and purification. [9] However, triethyl phosphate can be used over shorter time periods and with few side reactions.

Leuch's method involves the use of Lewis acids which converts the amino acids into alkyl chlorides e.g., Nethoxycarbonyl and N-methoxycarbonyl amino acid chlorides, $[10,11,12]$ then NCAs.' Other Lewis acids include bromides such as phosphorus penta-chloride since they were found to cyclize free amino acids more readily than the acid chlorides. See Figure 1. [13]

However, dichloromethyl methyl ether and oxalyl chloride are better Lewis acids, together with other reagents such as Dichloromethyl methyl ether yield pure NCAs'. Their greatest advantages are the relatively low reactivity that does 
not interfere with the amino acids side groups.

Previous work focused on synthesis of five-member hetero-cycle rings (NCAs') from an amino acid. The NCAs were then polymerized to form block polypeptides. Deming et al synthesized polypeptides, from NCAs', using organometallic catalysts under controlled conditions. His method of synthesizing achieved molecular weights up to $25000 \mathrm{Da}$ with low polydispersities. His group then went on to synthesize block co-polymers such as poly-L-lactide-coglycolide (PGLA) [14] and poly- $\varepsilon$-caprolactone- $c o$-glycolic acid-co-serine (PCGS) [15] using the same catalyst. This was done, by introducing different monomers after the initial monomer was consumed. More work has been done in the area, where di and tri-cyclic monomers were synthesised into stereo-specific polymers from cyclic monomers. [16]

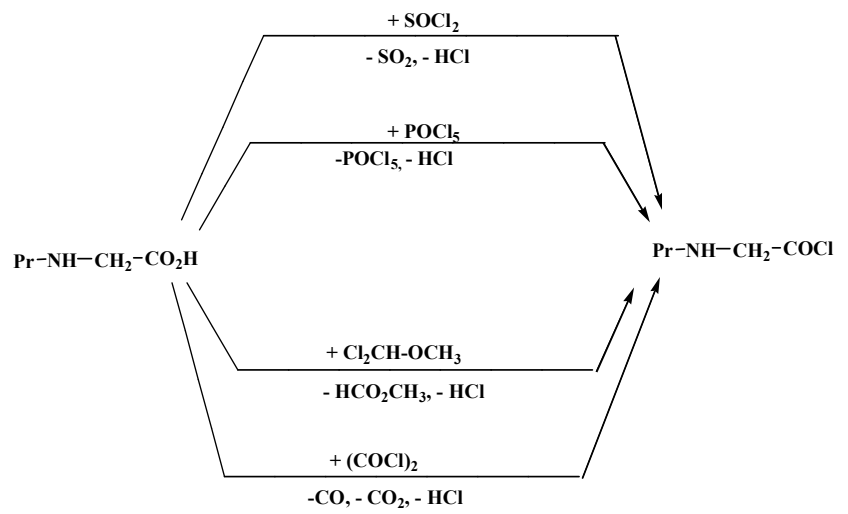

Figure 1. Synthesis of NCA precursors from various reagents.

The purpose of this paper is to report the preparation and characterization of cyclic monomer '4-methyl-1, 3, 6oxadiazocane-2, 5, 8-trione' (NCA-Alanine Glycine (NCA $\mathrm{AG})$ ) by wet synthesis. Alanine-glycine is a part sequence of silk, which is (Alanine-Glycine) ${ }_{3}$ Serine. Silk is widely recognised as the strongest polypeptide known of its size. [17] Attempts to synthesize a monomer to form silk polypeptides, [18] used dry chemistry and achieved up to six units of peptide. I will declare the synthesis of the NCA monomer $\mathrm{s}$ to form a nine-membered hetero-cycle ring NCA$\mathrm{AG}$ and a polymer of immeasurable $\mathrm{Da}(>1$ million Da).

\section{Experimental}

\subsection{Materials}

Oxalyl chloride, potassium sulphate, magnesium sulphate, sodium bicarbonate and sodium hydroxide were obtained from Sigma Aldrich; silica gel and 2-(2-(tert-butoxycarbonyl) propanamido) acetic acid was obtained from Advanced ChemTech, South Africa and was used without further purification. THF, DMF, acetonitrile, and diisopropyl ethylamine were purified by re-distillation before use. Water was obtained from an onsite distilling and deionising system.

\subsection{Equipment Used}

All amino acids and peptides were characterized by their melting points and $R_{f}$ values (product front vs. solvent front), and by nexus FTIR, Oxford-NMR and Proteomics using a CapLC coupled with a Q-TOF Ultima ESMS. The melting points were noted with Perkin Elmer, melting point instrument (DMA 8000). Product front vs. solvent front was utilized from thin layer chromatography (TLC) using appropriate solvent systems. Nicolet Nexus FourierTransform infrared (FTIR) was used to characterize 'fingerprint' spectrums of organic molecules. A nexus FTIR instrument was used under inert conditions to improve the signal: noise ratios, and obtain better spectra. All the above instruments are in University of Stellenbosch, South Africa.

Molecular masses were obtained with time-of-flight electro-spray mass spectrometry (TOF-ESMS). Ionization by spray techniques are based on desorption of the ions of a compound from a chromatographically separated liquid solution, with a mobile phase that contains an electrolyte.

\subsection{Cyclization of 2-(2-(Tert-Butoxycarbonyl) Propanamido) Acetic Acid (NCA-AG)}

A solution of DMF (3.72 mmol, $0.2 \mathrm{ml})$ was cooled to $(-20$ $\left.{ }^{0} \mathrm{C}\right)$ and freshly distilled acetonitrile $(10 \mathrm{ml})$ was added dropwise to oxalyl chloride $(0.62 \mathrm{mmol}, 0.054 \mathrm{ml})$. [19] After 30 min of stirring, Boc-AG-OH $(0.62 \mathrm{mmol}, 300 \mathrm{mg})$ and diisopropylethylamine $(0.62 \mathrm{mmol}, 0.088 \mathrm{ml})$ were added from a separate flask with acetonitrile $(2 \mathrm{ml})$ and cooled to $0^{0} \mathrm{C}$ and then further cooled to $-20^{\circ} \mathrm{C}$. After $2 \mathrm{~h}$, the mixture was allowed to warm up to room temperature (over a period of $1 \mathrm{~h}$ ) and stirred for a further $4 \mathrm{~h}$. The reaction was quenched, by pouring the reaction mixture on ice. The product was extracted into ethyl acetate $(3 \times 10 \mathrm{ml})$, dried over ' $\mathrm{MgSO}_{4}$,' the filtrate was dried under vacuum to afford the desired NCA-AG crystals. Recrystallization from ethyl acetate yielded yellow crystals with m. p. $114{ }^{\circ} \mathrm{C}$, in $65 \%$ yield. The reaction scheme is presented in Equation 1.

The dimer (Boc-AG-OH) and was cyclized to form 'NCA-AG/ 4-methyl-1, 3, 6-oxadiazocane-2, 5, 8-trione' in equation 1.

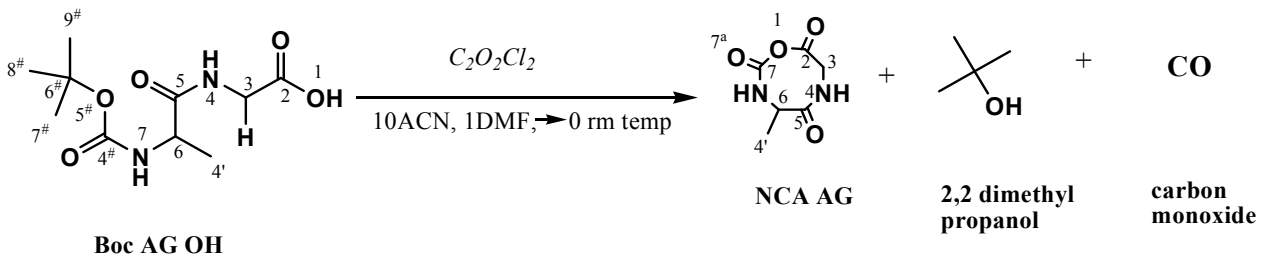


NCA-AG/ 4-methyl-1, 3, 6-oxadiazocane-2, 5, 8-trione

Yield: $66 \%, \mathrm{Mp}=134.3 \mathrm{C}$, Chromatograph-EthOAc: hex, (2:1), $\mathrm{R}_{\mathrm{f}}$ 0.26; MS (EI:-1.74 $\left.6 \mathrm{kV}\right) \mathrm{m} / \mathrm{z}: 98\left(\mathrm{DMF}+\mathrm{Na}^{+}+2 \mathrm{H}^{+}\right)$, $113\left(\mathrm{TEA}+12 \mathrm{H}^{+}\right), 172\left(\mathrm{M}+\mathrm{H}^{-}\right)$, FTIR $(\mathrm{KBr}$ discs$): 1375$ (m/def) $\mathrm{CCH}_{3}, 1721(\mathrm{~s} / \mathrm{str}) \mathrm{C}=\mathrm{O}, 1691$ (s/str) $\mathrm{C}=\mathrm{O}, 1649$ (s/str) C=O, 1110 (m-w/str) CN, 1264 (s/str) CO-NH,

${ }^{1} \mathrm{H}$ NMR $\left(600 \mathrm{MHz}, \mathrm{DMSO}_{3}\right): 1.14[3 \mathrm{H}, \mathrm{t}(J=7.3,7.9 \mathrm{~Hz})$, $\left.\beta-\mathrm{CH}_{3}\right], 3.41[1 \mathrm{H}, \mathrm{q}(J=4.3,5.2,4.3 \mathrm{~Hz}), \alpha \mathrm{CH}], 3.37[1 \mathrm{H}$, $\mathrm{t}(J=3.29 \mathrm{~Hz}), \alpha-\mathrm{CH}], 4.03[1 \mathrm{H}, \mathrm{t}(J=7.14 \mathrm{~Hz}), \alpha-\mathrm{CH}], 4.89$ $[1 \mathrm{H}, \mathrm{d}(J=7.2 \mathrm{~Hz}) \mathrm{Hz}), \mathrm{NH}], 8.06[1 \mathrm{H}, \mathrm{t}(J=7.2 \mathrm{~Hz}), \mathrm{NH}],{ }^{13} \mathrm{C}$ NMR (150 MHz, DMSO): $19.32\left[\left(\mathrm{CH}_{3}\right), 44.91\left(\mathrm{CH}_{3}\right)\right], 50.33$ $\left(\mathrm{CH}_{2}\right), 157.84$ [carbamate $\mathrm{C}=\mathrm{O}$ ], 172.62 [Gly $\mathrm{C}=\mathrm{O}$ ], 173.44 [Amide $\mathrm{C}=\mathrm{O}$ ]

\section{Results}

The percentage yields melting points values of NCA dimers were considerably low, possibly due to the packing of
NCA. They were relatively harder to synthesize.

To demonstrate the cyclisation of the dimer, rather than it's partially protected form, I analyzed the' cyclic monomer NCA-AG ion and its salts using electro-spray mass spectrum (ESMS). Clear peaks are seen for the NCA in the spectrum presented in Figure 2. The ESMS of selected ions of NCA$\mathrm{AG}$ and its salts, are shown; $m / z$; $\left(\mathrm{EI}:-1.74^{\mathrm{e}} 6 \mathrm{kV}\right) ; 98$ $\left(\mathrm{DMF}+\mathrm{Na}^{+}+2 \mathrm{H}^{+}\right), 113\left(\mathrm{TEA}+12 \mathrm{H}^{+}\right), 172\left(\mathrm{M}+\mathrm{H}^{-}\right)$, FTIR $(\mathrm{KBr}$ discs): 1375 (m/def) $\mathrm{CCH}_{3}, 1721$ (s/str) $\mathrm{C}=\mathrm{O}, 1691$ (s/str) $\mathrm{C}=\mathrm{O}, 1649$ (s/str) $\mathrm{C}=\mathrm{O}, 1110$ (m-w/str) CN, 1264 (s/str) CO$\mathrm{NH}\left({ }^{\prime} \mathrm{M}\right.$ ' denotes 'NCA-AG $=172.14 \mathrm{~g} / \mathrm{mol}$, whilst the number of ions bonded to it is shown together with the collective charge. Boc-AG-OH does not show a peak at the expected position, confirming the absence of unprotected amine. The above, presented data should be viewed as qualitative description of the protecting of the amine and not an attempt at quantization of the products.

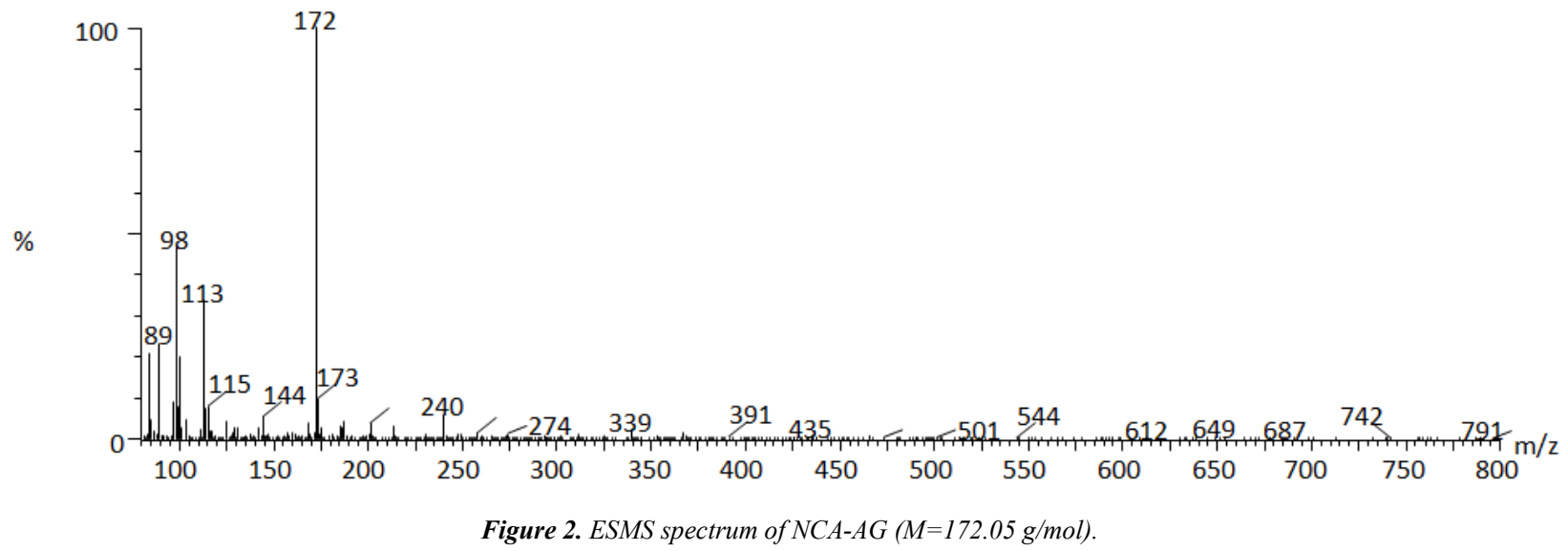

The FTIR spectrum in Figure 3 shows the fingerprints of the molecular structure of the dimer NCA-AG. Points to observe are the absence of 'boc' $\mathrm{C}\left(\mathrm{CH}_{3}\right)_{3}$ groups $4^{\#}$ to $7^{\#}$, increased intensity of amide bonds ' $\mathrm{CO}-\mathrm{NH}^{\prime} 4-\mathrm{C} 5$ at 1220 to

$1020 \mathrm{~cm}^{-1}$ range, decrease in amino acid groups and an upfield shift in carbonyls peaks for the carbamate range to 1649 to $1747 \mathrm{~cm}^{-1}$ (s/str).

\section{$\underline{\text { NCA-AG }}$}

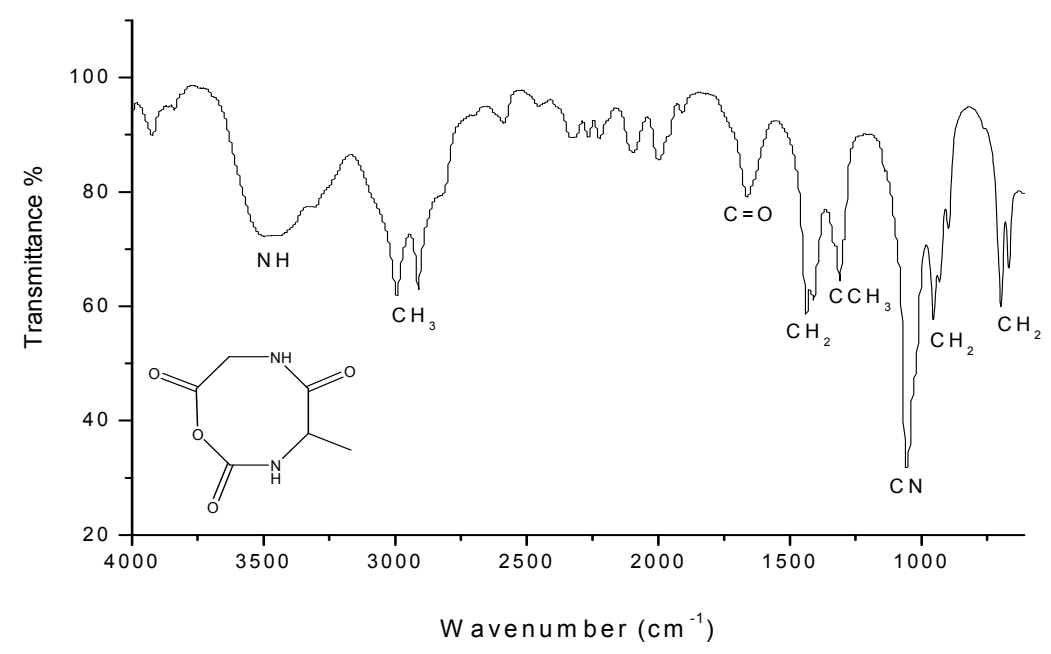

Figure 3. FTIR spectrum of NCA-AG. 
In general there is an up-field move, especially with the amides and an absence of boc groups $\left(\mathrm{C}^{\sharp}\right)$, as seen in the proton spectrum of dimer-NCAs that is a by-product of the cyclization reaction. This can be seen in the spectra shown.

Likewise the main difference in the carbon spectra for the peptide precursor and NCA is the absence of the 'boc' functional groups that is eliminated in the cyclization reaction. This can be observed in the carbon spectrum, where the characteristic peak of the 'boc' functional group would normally be found at frequency ranges of 1500 to $1600 \mathrm{ppm}$ in the carbon spectrum.

\section{Conclusion}

DMF was used as a standard solvent for cyclization, DIPEA as a proton grabber and oxalyl chloride $\left(\mathrm{CO}_{2} \mathrm{Cl}_{2}\right)$ as the cyclising regent for the dimer cyclisaton. Oxalyl chloride was the most optimum cyclising agent for Boc-Ala-Gly-OH cyclisaton, as it's by products were easy to remove. The optimum temperatures were $-20^{\circ} \mathrm{C}$ initially to $30^{\circ} \mathrm{C}$ for the dimer cyclization. In this case, the dimer, 'Boc Ala-Gly OH' was investigated and an example of the reaction is illustrated in equation 2 below.

$$
\mathrm{Bocdimer}-\mathrm{OH}_{(\mathrm{g})}+\mathrm{CO}_{2} \mathrm{G}_{2(\mathrm{~g})} \underset{0 \sim 100^{\rho} \mathrm{C}}{\frac{R^{\prime \prime} \mathrm{NH}}{\sigma}} \mathrm{NCAdimer}+\mathrm{HC}_{(\mathrm{g})}+2 \mathrm{CO}_{\mathrm{g}}+2 \mathrm{CH}_{3} \mathrm{OH}_{(\mathrm{I})}
$$

Equation 2. Cyclizing of dimer with Lewis acid.

The most optimum conditions, which gave the highest yields for the cyclization reactions of NCA-AG were found to be those using dimethyl formamide (ACN/DMF) as a solvent. The best proton grabbers were found to be tertiary bases with oxalyl chloride as the Lewis acid. Temperatures were best kept as low as $-20^{\circ} \mathrm{C}$ for the first hour of the reaction and gradually brought to room temperature thereafter, for the dimers. All factors such as solvents, temperature and proton grabbers were optimized to push the equilibrium of the reaction forward. Attempts were made to improve yields of the NCA dimers by using other Lewis acids such as triphos, however, the yields were rather low and it was more difficult to clean up the products too. Reaction equilibrium seemed to favour polymerization to cyclization, where polymers at elevated temperatures conditions with immeasurably high molecular weights of poly (Ala-Gly) amide, were synthesized instead of the NCA dimer on occasion.

Reduced stability of the NCA dimer ring could have been due to the small and restrained angle formed in the ring. Furthermore, the $\mathrm{sp}^{3}$ hybridisation did not play much of a role in the stability of the NCA-AG dimer ring. NCA dimers were challenging to cyclise, partly due to their reactivity and low bench standing time.

\section{Acknowledgements}

The authors wish to thank the staff at the University of Stellenbosch, particularly, Mrs. E. Cooper and Mrs. M.
Hundall, for their contribution to this work. They would also like to thank the National Research Foundation of South Africa for funding the research, Professor Harald Pasch and colleagues at the Deutsches Kunkstoff-Institut for all the analysis and funding of my work in Germany. Finally, the contributions made by the department of Chemistry and Polymer Science and the University of Stellenbosch library, are gratefully acknowledged.

\section{References}

[1] Stainslaw, P. (2000) Models of Biopolymers by Ring Opening Polymerization, Ch 1, CRC Pr ILIc, Berlin, NY.

[2] Deming, T. J., (2000), "Living polymerization of $\alpha$-amino acid-N-carboxyanhydrides." J. of Polym. Sci. Part A, 38, 3011-3018.

[3] Deming, T. (2000), "Chain initiation effeciency in cobalt and Nickel mediated polypeptide synthesis“ J. Am. Soc., 122, 5710-5717.

[4] Zhang, S., Anderson, M. A., Ao, Y., Khakh, B. S., Fan, J., Deming, T. J., Sofroniew, M. V., (2013), "Tunable diblock copolypeptide hydrogel depots for local delivery of hydrophobic molecules in healthy and injured central nervous system," Biomats., 35, 6, 1989-2000.

[5] Jiang, Z. K., Koh, S. B. S, Sato, M., Atanasov, I. C., Johnson, M., Zhou, H, Z. and Deming, T. J. and Wu, L. (2013), "Engineering polypeptide coatings to augment gene transduction and in vivo stability of adenoviruses," J. Control. Releas., 166, 1, 75-85.

[6] Song, B., Song, J., Zhang, S., Anderson, M. A., Ao, Y., Yang, C. Y., Deming, T. J., Sofroniew, M. V., (2012), "Sustained local delivery of bioactive nerve growth factor in the central nervous system via tunable diblock copolypeptide hydrogel depots" Biomats. 33, 35, 9105-9116.

[7] Tanimoto, S. Yagi, N. and Yamaoka, H., (2009), “Application of Thermosensitive Peptide Copolymer Gels to Removal of Endocrine Disruptor," Research Letts in Mat. Sci., 2009, 1155.

[8] Jap. Pat. 6.901 .974 (1969) to Asahi Chem. Ind.; invs. Wakasa, R., hibata, K., Takahashi, Y., Ishida, S.: CA 71, 13, 373-374.

[9] Levy, A. L. (1950), 'Anhydro-N-Carboxy-DL- $\beta$ Phenylalanine,' Nature, 165, 4187, 152-152.

[10] Iwakura, Y., Uno, K. and Kang, S. (1965), "Trisphosgene, a crystalline phosgene substitute," J. polym. Sci (part A-1)," polym. chem., 30, 4, 2867-2879.

[11] Kricheldorf, H. R. (1966) Chem. Ber., 87, 104, 3168-3175.

[12] Cheng, J., Ziller, J. W. and Deming, T., (2000) "Synthesis and Conformational Analysis of Optically Active $\operatorname{Poly}(\beta-$ peptides)"J. Org. Lett., 2, 13, 143-146.

[13] Leuchs, H. \& Geiger, W. (1908), "Über die Anhydride von $\alpha$ Amino- $N$-carbonsäuren und die von $\alpha$-Aminosäuren," Dtsch.Chem, Ges., 41,1721-1726.

[14] Salamula, E. J., Bredenkamp, M., Bezuidenhout, D. and Nadiye. M. S., (2015), Optimizing of "N - tert - butoxycarbon anhydrides polymerization of NCAs' AG, SIK and VAV", Int. Appl. Chem., 11, 4, 409-426. 
[15] Wagner S., and Prentice B., Hall Englewood Cliffs, [Online] NJ07632, www.scribd.com/doc/7365634/Superstrong-MaterialBioSteel pp 18-25.

[16] Klok, H. H., Gotz, R. S. (2004), "Synthesis of a silk-inspired peptide oligothiophene conjugate"Org. Biomolecul. Chem. 2, 24, 3541-3044.
[17] Daly, W. H. \& Poche, D., (1988), "Synthesis of a PEG- $b$ PAsp- $b$-PPhe Triblock Copolymer.” Tetrahedron Lett., 29, 46, 5859-5862. 